\title{
Only-Bus System for intercity mass transit to reduce several numerous road traffic accidents
}

\author{
P. E. Faye, H. Azuma \& I. Yoshida \\ School of Urban Environmental Sciences, Department of Tourism, \\ Tokyo Metropolitan University, Japan
}

\begin{abstract}
Senegalese intercity mass transit is dominated by very dilapidated minibuses and unsafe buses and the main roads are not in a good condition for either daytime or night time driving. During the rainy season, many roads are passable only with four-wheel drive vehicles. Due to the poor quality of road infrastructure and the outdatedness of the car fleet, crash risks are high and accidents are very frequent in Senegalese intercity mass transit. The road accidents kill an average of 350 persons and injure 2100 persons a year in Senegal. To overcome this problem of lack of safety, this paper focuses on a new kind of bus-based transit system called Only-Bus System (OBS) to introduce an innovative transit system for significantly reducing the road traffic accidents in Senegal. Analysis was conducted by gathering information from transportation membership and corporations in Senegal, reviewing papers from the USA, Europe, Asia and beyond, etc. The findings show that: 1) the real need of the system is to impose better bus services as the only public road intercity transit mode; 2) neither minibuses nor intercity taxi services will occur in this system; 3) The restriction of small occupancy vehicles and private cars and the introduction of high quality and large size buses could solve both the road traffic accidents and intercity travel demand.

Keywords: Only-Bus System, intercity mass transit, accident problem, high quality bus, safety and security.
\end{abstract}

\section{Introduction}

The problems of urban transportation for developing and underdeveloped countries are permanent. In fact, it has become more and more urgent to find 
sustainable solutions to these problems. Displacements between cities require a minimum of safety as well as transportation mode and the road infrastructures. The most important problem, notable in the African transport system, is the lack of safety (e.g. Amegashie [1]).

Nowadays, transport in Senegal is facing a big challenge due to multiple traffic accidents. Road traffic crashes are getting more and more important and are becoming the biggest traffic problem in Senegal. One of the biggest problems which concerns the Senegalese government remains the improvement of road safety, considering the scale of the phenomenon. It is thus necessary and urgent to find, at every level, a way of reducing traffic accidents or simply their eradication.

Road accidents result in an average of 350 persons killed and 2100 injured a year in Senegal. It is necessary to note that after malaria, it is the roads which kill most people in Senegal. Nevertheless, Africa is the continent where roads are less numerous and the level of motorization even weaker. In Senegal, the problem of the standard of the roads and the numerous accidents deserves our attention more than ever.

Senegal is located in the west of Africa. It covers a land area of almost $197,000 \mathrm{~km}^{2}$, which includes $531 \mathrm{~km}$ of coastline along the Atlantic, and has an estimated population of about 14 million. The climate is tropical with two seasons: the dry season and the rainy season. Senegal is externally bounded by the Atlantic Ocean to the west, Mauritania to the north, Mali to the east, and Guinea and Guinea-Bissau to the south.

There are approximately $3900 \mathrm{~km}$ (2423 miles) of asphalt roads linking the major towns and the coastal region. The network of roads in the interior is rough (about $10,400 \mathrm{~km} / 6460$ miles in total) and may become impassable during the rainy season; it is not advisable to drive at night.

This paper will be divided into three parts: the first will focus on the current intercity transit system, the second will be about the trends of the Senegalese intercity road crashes and the last point will speak about a new intercity transit system.

\section{Objectives and purposes}

The aims of this paper are to define a new generation of high quality bus system called Only-Bus System (OBS) for Senegalese intercity transit in order to develop an innovative transit system and to significantly reduce road traffic accidents in Senegal. Therefore it will be important:

- To reduce the use of private cars for intercity road travel and promote the development of effective solutions to increase road safety.

- To identify all requirements of "Only-Bus Systems" and their components (vehicle, operation, infrastructure).

- To demonstrate the full potential of the new "Only-Bus System" concept, produce a new handbook to guide and recommend authorities and operators, giving crucial keys on implementing the new generation of "Only-Bus networks". 


\section{Methods and research proceedings}

Both qualitative and quantitative investigation methods were used to conduct this study.

First of all, information from transportation membership and corporations were gathered to:

- Conduct a literature review of existing intercity mass transit and of the methods other states are using to enhance intercity bus travel.

- Analyze the database provide by the Senegalese Earth Transport Direction (DTT) and the Senegalese Statistical Direction (DPS), to find out how much the normal bus size is lacking for intercity transport and its responsibilities for road traffic crashes.

- Evaluate the infrastructures and facilities of intercity carriers and the status of current intercity bus services.

This third stage helped us to define the process of implementation of the OBS proposed with the Policy Formulation because, once all databases have been completed and analyzed, 'target groups' that will help us propose a new transit policy will be identified.

Once the policies have been formulated, the conditions to implement an OnlyBus System will be easily defined.

\section{Analysis of the current intercity traffic situation}

It is clear that Senegal has experienced a big delay in the acquisition of quality road infrastructures while existing roads deteriorate.

Senegalese roads have become cemeteries while the methods of transportation are rolling coffins, as the accidents are very fatal; there is a level of advanced degradation of the majority of roads, an indiscipline of the majority of the drivers, in particular those of the public transportation, and an outdatedness of the car fleet.

Road transport is the dominant mode of transport in Senegal; it is responsible for $90 \%$ of movement of persons and goods.

The Senegalese car fleet increased considerably in the 1990s. Due to the import of second-hand diesel vehicles, the registered number of cars multiplied by more than 6 between 1990 and 2000 .

The car fleet of Senegal consists of many kinds of vehicles, but individual cars are by far the most numerous, with making up nearly $70 \%$. Public transport vehicles, such as buses and minibuses, are the minority sector of transport in Senegal; they make up only $7 \%$ of the car fleet.

The Senegalese car fleet is old; it consists of cars which are too old. In spite of the ban from importing cars which are more than 5 years old, $70 \%$ of the cars are more than 16 years old. This old age concerns all kinds of vehicles but "car rapide" and "Ndiaga Ndiaye" remain the oldest transportation modes. This outdatedness of cars does not facilitate the eradication of accidents [2]. 


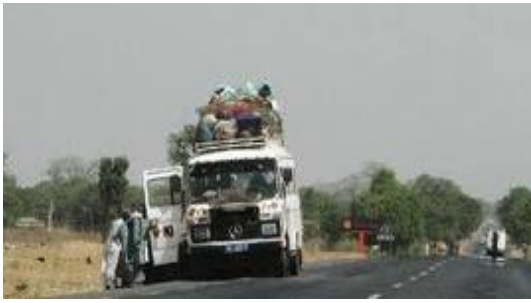

Figure 1:
Senegalese intercity minibus with luggage on the top.

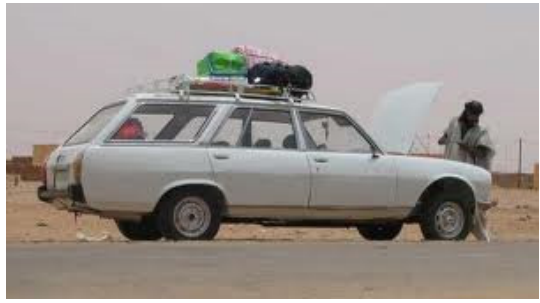

Figure 2: $\quad$ Senegalese intercity taxi with luggage on the top.

\subsection{Overview of intercity road traffic crashes and injuries in Senegal}

The World Bank studies show that bad roads, dilapidated vehicles and lax regulations so often have fatal consequences. At the world level, the percentage of fatal accidents on African roads is three times higher among vehicle numbers (e.g. Bliss and Breen [3]).

Since 2002, whatever the considered year, more than $40 \%$ of the accidents in Senegal took place in intercity traffic, about $58.6 \%$ on average a year. Many accidents are also noticed on main roads; in 2004 they were only $13 \%$, but in 2006 they were around $17 \%[4]$.

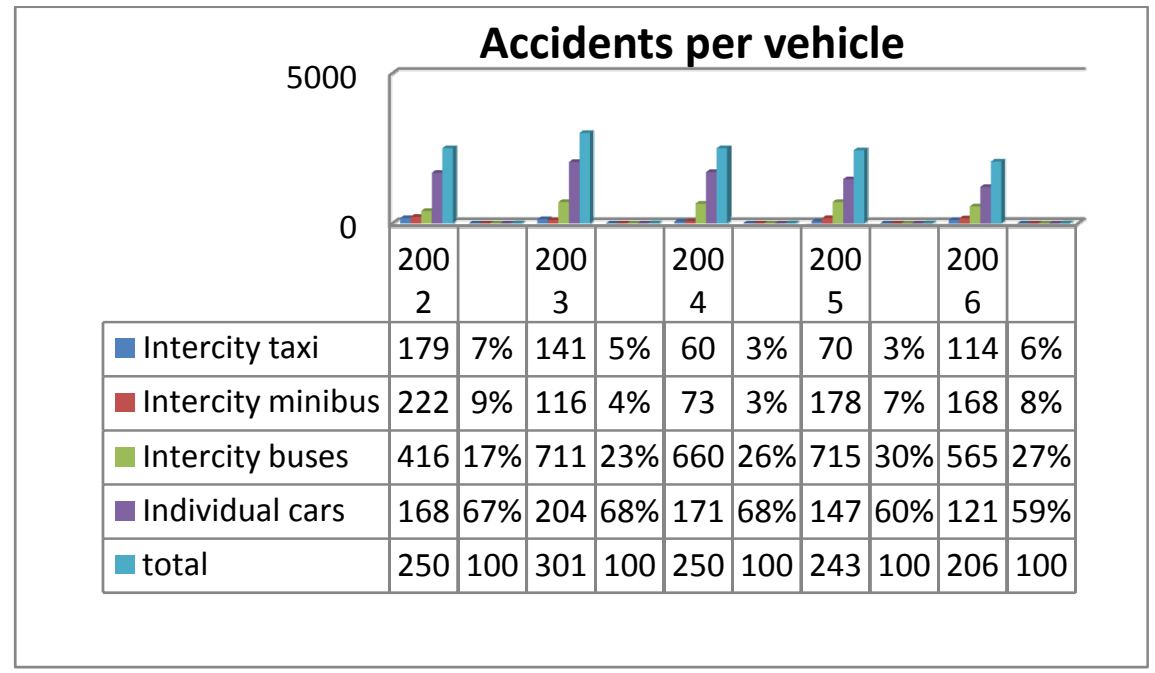

Figure 3: Accident numbers per vehicle.

From 2002 to 2006, the vehicle accidents concerned mostly those transporting persons (more than 8 accidents in 10). Vehicles transporting goods were $3 \%$ of accidents on average. 
It is the individual cars which are the most affected by the accidents. From $67 \%$ of the accidents in 2002, this percentage of car accidents increased to $68 \%$ in 2004 and fell to $59 \%$ in 2006 .

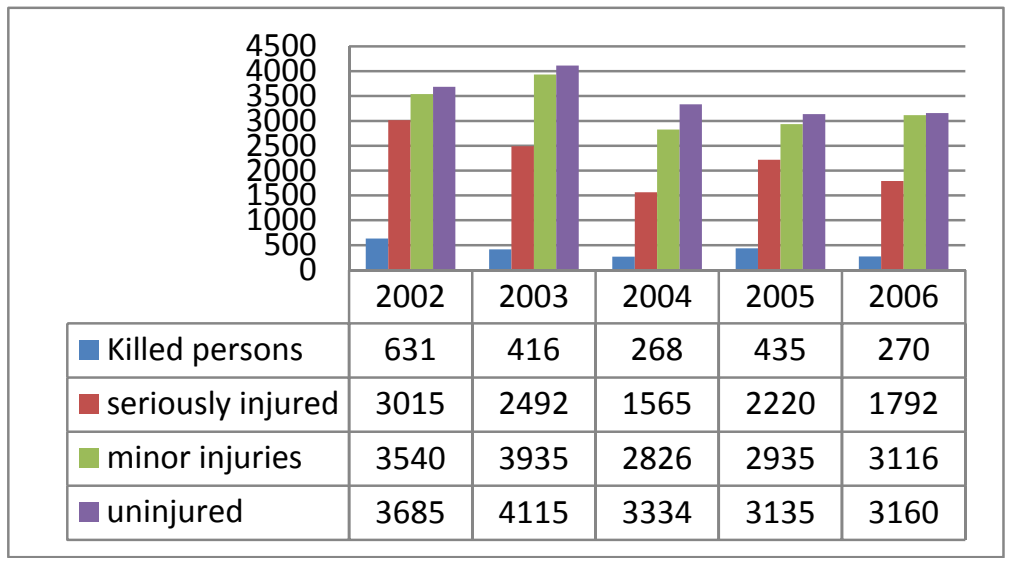

Figure 4: Figure of accident consequences.

These types of vehicles are followed by intercity buses with $26 \%$ of the accidents in 2004; the accidents caused by those vehicles increased in 2006 and are still numerous today. The intercity taxis are also responsible for $24 \%$ of road accidents over the period 2002-2006 [5].

Passengers are a very important category during the accidents, they constitute persons killed, persons badly injured but also the most numerous are persons who are slightly injured. Of 100 accident victims killed in 2006, 44 were passengers. This rate was $64 \%$ in 2002 . Drivers came second place with $17 \%$ of the persons killed on average over the period.

In a sample of African countries, 339 deaths for 10000 vehicles were recorded in 1996. By comparison, the rate of death in the ten most motorized countries of the world was 2.3 for 10,000 vehicles this year, according to the Global Road Safety Partnership, the body concerned with road safety around the world.

The road in Senegal is a very dangerous area where people can easily lose their lives; from 2002 to 2006 about 2020 people lost their lives on roads, 11,086 people were seriously injured while 16,352 were slightly injured, and one can note that the unscathed persons are 17,429.

Roads in Senegal have caused damage and continue to do so; the number of victims is too large while the number of passengers and vehicle remains limited. However in developed countries where there are more vehicles, more travellers and greater speeds, the number of casualties is low even if it is disturbing. To eradicate this problem which is almost chronic in Senegalese mass transit, it will be important to know the reason for road accidents (e.g. Diagne [6]). 


\subsection{Numerous traffic accidents problem and causes}

Table 1: $\quad$ Causes of accident figures.

\begin{tabular}{|c|c|c|c|c|}
\hline $\begin{array}{c}\text { Reason for } \\
\text { accidents }\end{array}$ & $\begin{array}{c}\text { Users' } \\
\text { behavior }\end{array}$ & $\begin{array}{c}\text { Car } \\
\text { fleet }\end{array}$ & Infrastructures & Others \\
\cline { 2 - 5 } & $63 \%$ & $19 \%$ & $7 \%$ & $11 \%$ \\
\hline
\end{tabular}

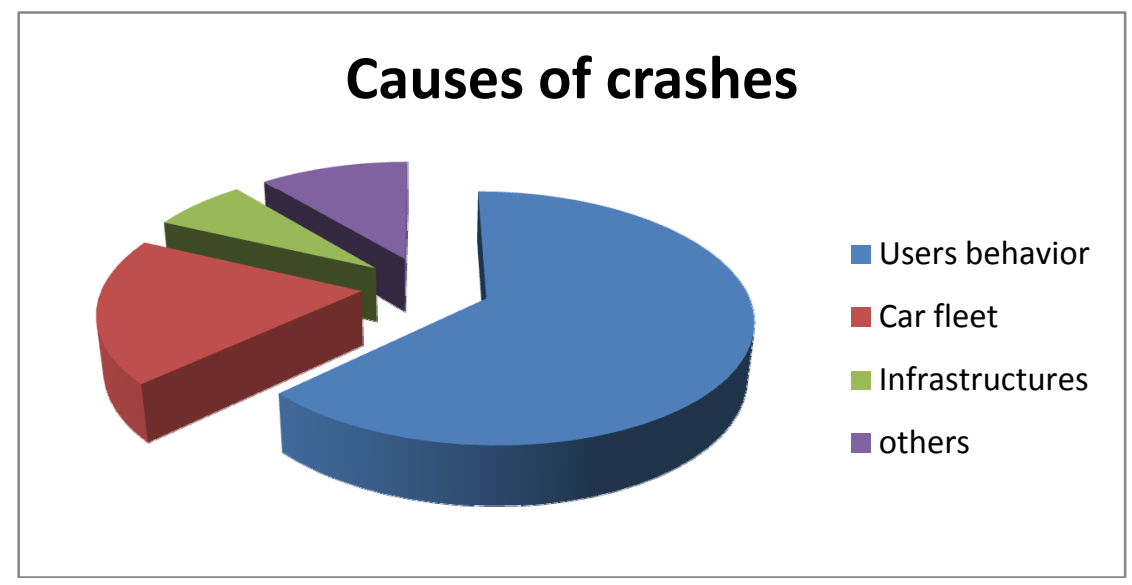

Figure 5: $\quad$ Causes of accidents.

\subsection{Analysis of accident risk in the intercity road system}

Transport is a high-risk exercise; it provides the pleasure of moving people and goods, but it also causes the misfortune of killing people and destroying goods. People are so often exposed to risks of road crashes, and there are many factors related to these accidents.

Speed is considered as the first problem in fatal crashes, so many studies suggest that there is a strong relationship between speed and accident rates. Researchers found that a vehicle moving much faster than the normal speed has more chance of being involved in a crash. No link, however, was found with a vehicle moving much slower than the normal speed (e.g. Jacobs and AeronThomas [7]).

Fatigue or sleepiness is also considered as crash factors; in Senegal these factors are more visible during the large national event such as Gamou, Magal or Tabaski when long-distance travel demands become too high. This situation is due to a lack of training and especially to an absence of motivation to be safe. Traffic law enforcement is almost absent in Senegal.

Other major accident factors are the conditions of vehicles and those of the roads. The intercity vehicles in Senegal are dilapidated, the average age is 16 years and capacity is very limited (e.g. Kumar and Diou [8]). The big problem with these vehicles is that when they are involved in an accident there are more possibilities to count the deaths rather than persons who are unhurt. 
Roads are also sometimes in a very bad condition, forcing vehicles to be at high risk during travel. So therefore is no Opportunity to Be Safe is given by the transport system in Senegal. Accident factors are known, and it is important to fix and banish them to create a better system of intercity transportation.

\section{Alternative and innovative system: the no risk theory (NRT)}

To understand road crashes, one should gather three elements: the driver, vehicle and road. The driver is certainly an important element in the traffic safety system but it is not the most important element. This is both the vehicle and the road which are more fundamental in transport (e. g. Rothengatter [9]). So, in order to reduce crash numbers or the severity of accidents, transport-planners and decision-makers should consider these elements as well. The risk is one important part of traffic, there is no traffic without risk; even if the three elements are well covered, some behavior (users, drivers) might be able to occasion risk.

Thus, improving the opportunity to be safe is meant to reduce the risk of crashes. So it is important to identify the different elements of accident risks and fix them. That is a way to determine the no risk theory.

The no risk theory has three dimensions: opportunity to be safe, motivation to be safe and the desire to be safe. The opportunity to be safe is provided by all the first three elements: driver, road design and vehicle option; however roads and vehicles are the most important [10]. If the road design meets the standard of safety and the vehicle option reaches a high level of quality, there will be a good opportunity to be safe, but it should be accompanied by enhancement of driver's education and qualifications.

The motivation to be safe is provided by traffic law enforcement effort; it should be based on a combination of practices taken seriously, with the development and promotion of a law enforcement operations planning system.

The desire to be safe should be the result of action based on a combination of training, experience and common sense; community participation will be key and will provide possible solutions to the risk problem. The desire for safety can also occur through partnership initiatives by involving all the road user organizations.

These three elements will considerably reduce the road accidents and can establish peace on the roads forever.

In view of these major transportation problems with the numerous accident risks, it is clear that the roads need a new system. Accidents would be reduced if we significantly reduce the risks and, if we refer to the theory of non-risk, it appears that the risks of accidents are caused by impassable roads, bad behavior and obsolete vehicles.

To resolve these risks then requires banishing this kind of infrastructure and equipment from the system, renewing it and redefining it completely. Therefore, we should think about a global system that combines high quality of infrastructure, vehicles with a high level of service and a modern management system. 
This system will not admit taxis and minibuses for road intercity mass transit; it will use a type of bus quality that meets international standards. This system meets the criteria of no risk theory; it can be called the Only-Bus System (OBS) and appears as a guarantee against serious road accidents.

\section{The safety system perspective: Only-Bus System concept}

As is already explained, the no risk theory requires a high quality of bus to give some opportunity to be safe. A good level of road and bus quality, and something else should be gathered to the OBS requirement.

\subsection{OBS concept, packaging and definition}

The Only-Bus System is an innovative approach to public road transport developed in order to promote an intercity bus image in Africa and also to enhance system safety and security in road travel (e.g. Stuart et al. [11]). It consists of a travel system in which the only intercity road public transport carrier is buses; neither minibuses nor intercity taxi service will be involved in this system.

This means that there will be no kind of transportation mode other than buses in the intercity road transit; all intercity public transit modes will be excluded from the system. OBS aspires to the comfort level offered by rail with bus-type infrastructures.

The system will combine modernity, quality, comfort and security; it will also gather quality bus travel, service efficiency and sustainability. Roads should also be practicable with a level of security provided; as for the drivers, they must be trained to meet the expectations of passengers and road safety stakeholders (e.g. Dayo [12]). Operators should be national, private or parastatal companies but not individual owners.

In this system, stations, vehicles, infrastructures and operations should be gathered consistently. The system is based entirely on the process of Bus Rapid Transit and intercity bus standards in developed countries (e.g. Manual and Angeles [13]). Vehicles should also be of high quality and high capacity, being the same size as those of developed countries. The system should also provide comfort, safety, efficient interchanges hubs and passenger information systems.

With this OBS proposed, travel times can be shorter than they are with the traditional intercity mode of transit by increasing the maximum speed on the road while providing the best security and safety warranty.

\subsubsection{Definition of OBS}

The Only-Bus System is a global intercity road mass transit that admits only buses as a travel mode excluding intercity taxis and minibuses and combines improved road network conditions, modern intercity bus terminals, high quality buses, high levels of safety, and ITS elements into an integrated system with a strong positive image and identity (e.g. Frittelli and Kirk [14]). In addition, it provides a service that operates with limited stops connecting two or more cities. 


\subsection{Requirements and implementation issues}

To implement OBS, planners and decision-makers should define at first the characteristics required in the whole system. In this paper five major elements of OBS are presented with their attributes.

\subsubsection{Requirement}

The most important element of OBS is the vehicle; it should be a highway vehicle configuration with an aesthetic enhancement, and a large size vehicle is required with a passenger circulation enhancement.

Road, station and terminal should be improved; OBS requires an intermodal terminal to facilitate transfer between different transportation modes. OBS can also have small stations with boarding information and a sheltered ticketing area. Another element is ITS to improve electronic services such as card and internet payments, advanced communication systems with real time travel and travellers' information at stations and on vehicles (e.g. Venkat et al. [15]).

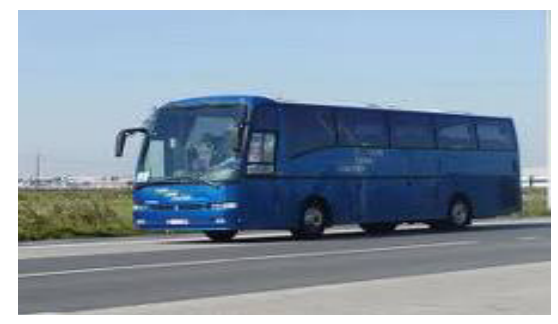

Figure 6: High quality bus.

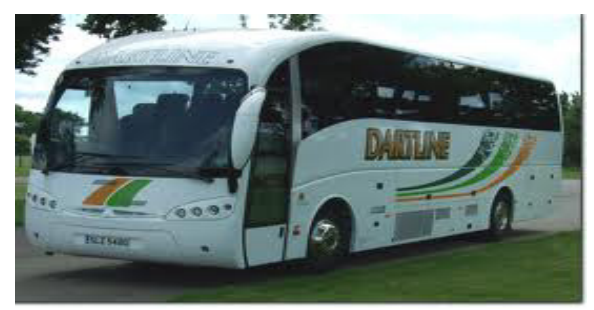

Figure 7: Aesthetic image enhancement.

The system also requires strong traffic law enforcement that includes control of vehicle options, the route used and drivers' qualifications. This system does not admit private/individual operators; the operators should be national, private or parastatal companies. 


\subsubsection{Vehicle option to reduce crash risk while increasing speed and capacity}

The OBS vehicle option presents three major characteristics: the bus should combine the criteria of performance, high service and appropriate identity. Vehicle performance is measured by three sub-criteria: high speed, practicality and high capacity (e.g. Olsson and Thynell [16]).

The high quality service also offers three sub-criteria that are high safety, spacious luggage compartments and ride comfort. As for appropriate identity, it has to present a service that features a pleasant interior and exterior which is aesthetic pleasing and of large size (e.g. Ponnaluri [17]).

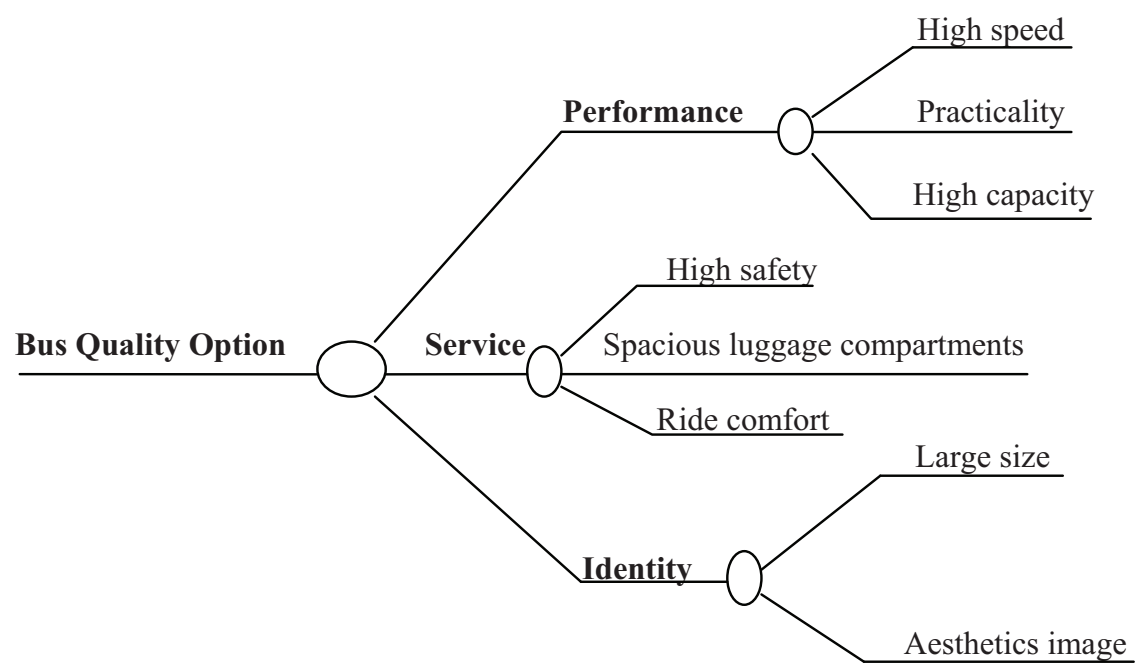

Figure 8: OBS vehicle quality option.

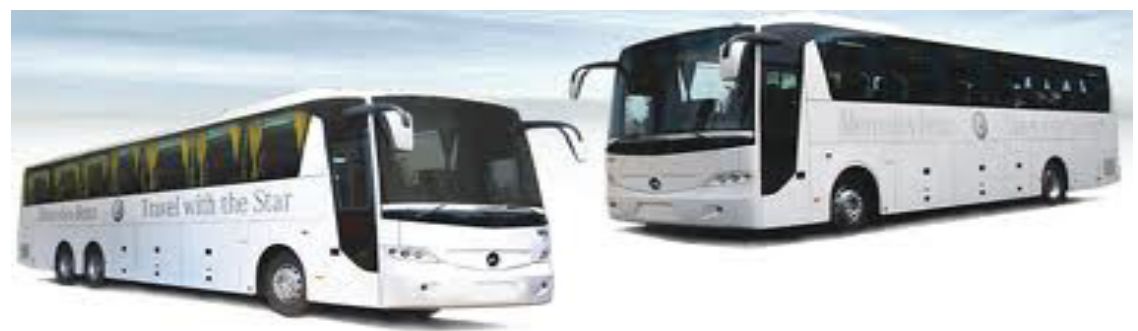

Figure 9: OBS vehicle option gathering different criteria. 


\section{Conclusion and recommendations}

For safety reasons, the U.S. Embassy in Senegal recommends its citizens not to use "cars rapides", "Ndiaga Ndiaye" and public transportation because of overloading, careless driving, inadequate maintenance, and the lack of basic safety equipment. So it is urgent for Senegalese decision makers to develop a coherent road safety policy, because road accidents have become a big scourge. The road accident rate is not negligible; the roads kill many people in Senegal.

However, Senegalese intercity road traffic crashes can be significantly reduced if this proposed Only-Bus System is taken seriously. OBS is an intercity road mass transit system that admits only high quality buses and excludes other kinds of road transit modes, such as minibuses or taxis.

With that system, the road crash risks will be very insignificant and fatalities will also be minimal because it suggests a better system, good road conditions, and a high standard of buses.

A real reduction of road crashes because of the system and fatal accidents because of the bus option is expected in this system.

\section{Acknowledgements}

Many thanks and gratitude is addressed to all staff (professors, students and administrators) of the Tourism Department of Tokyo Metropolitan University for their technical support, advice, guidance, criticism and encouragement.

\section{References}

[1] Amegashie, J. M Y., African Road Safety Conference, Road safety and poverty, Accra, Ghana, pp. 1-13, 2007.

[2] Conseil Exécutif des Transports Urbains de Dakar, http://www.cetud.sn/

[3] Bliss T., Breen J., Implementing the Recommendations of the World Report on Road Traffic Injury Prevention, the World Bank Global Road Safety Facility, Washington DC, pp. 3-49, 2009.

[4] Sénégal. Agence Nationale de la Statistique et de la Démographie, http://www.ansd.sn/.

[5] Gouvernement du Sénégal, http/ /www.gouv.sn/spip.php?article751.

[6] Diagne S., Rapport de diagnostique sur la vulnérabilité aux changements climatiques du secteur des infrastructures au Sénégal, Programme d'assistance des Pays Bas sur le climat phase 2, 2006.

[7] Jacobs G and Aeron-Thomas A., Africa road safety review, final report, US Department of Transportation/Federal Highway Administration, pp 1-100, 2000.

[8] Kumar A. and Diou C., Bus Renewal Scheme in Dakar, SSATP discussion Paper No. 9, Urban Transport Series, pp 1-95, 2010.

[9] Rothengatter, T., Drivers illusions no more risk, Elsevier Science Ltd., Transportation Research Part F 5, pp. 249-258, 2002.

[10] http://www.husdal.com/category/book-review/. 
[11] Stuart M. Stephen I. \& Marcus E., Evaluating alternative concepts of busbased park and ride, Transport Policy, 18, pp. 456-467, 2011.

[12] M. Dayo, Lagos Bus Rapid Transit, Africa's first BRT scheme, SSATP Discussion Paper No. 9, Urban Transport Series, pp. 1-54, 2009.

[13] Manual G. D., Angeles M. S, Some lessons from incentive theory: Promoting quality in bus transport, Transport policy, 18, pp 299-306.

[14] Frittelli J. and Kirk S. R., Amtrak: The Political and Social Aspects of Federal Intercity Passenger Rail Policy, CRS Report for Congress, pp. 137, 2004.

[15] Venkat P. et al., Applicability of Bogota's Transmilenio BRT system to the United States, Final report: Washington, 2006.

[16] Olsson L., Thynell M., Bus Project in Dhaka, Bangladesh Road Transport Corporation (BRTC), Edita Communication AB, Stockholm, pp. 9-26, 2006.

[17] Ponnaluri V. R., Sustainable Bus Rapid Transit initiative in India: the role of decisive leadership and strong institutions, Transport Policy, 18, pp. 269-275, 2011. 